Article

\title{
Strengthening of RC Slabs with Symmetric Openings Using GFRP Composite Beams
}

\author{
Yeol Choi ${ }^{1}$, Ik Hyun Park ${ }^{1}$, Sang Goo Kang ${ }^{1}$ and Chang-Geun Cho ${ }^{2, *}$ \\ 1 School of Architecture \& Civil Engineering, Kyungpook National University, Daegu 702-701, Korea; \\ E-Mails: choiyeol@knu.ac.kr (Y.C.); gale6138@naver.com (I.H.P.); ksg12312@naver.com (S.G.K.) \\ 2 School of Architecture, Chosun University, Philmundaero, Dong-Gu, Gwangju 501-759, Korea \\ * Author to whom correspondence should be addressed; E-Mail: chocg@ chosun.ac.kr; \\ Tel.: +82-622-307-023; Fax: +82-622-307-155.
}

Received: 28 October 2013; in revised form: 25 November 2013 / Accepted: 27 November 2013 / Published: 3 December 2013

\begin{abstract}
This paper describes the results of experimental testing of glass fiber reinforced plastic (GFRP) composite beam strengthened reinforced concrete (RC) slabs with two symmetrical openings. Specimens, one-half scale, have been designed and fabricated to reflect the most common RC bathroom slab used in school buildings. The specimen had dimensions of $2000 \mathrm{~mm}$ (width) $\times 150 \mathrm{~mm}$ (thickness) $\times 3000 \mathrm{~mm}$ (length) were used with the two openings of $300 \mathrm{~mm} \times 400 \mathrm{~mm}$. The aim of this study is to investigate the most effective strengthening method using GFRP composite beams in slabs with openings for enhancing the load-carrying capacity and stiffness. Test results showed that the strengthened slabs seems to increase the load-carrying capacity by $29 \%, 21 \%$ and $12 \%$ over that of the control specimen for diagonal, parallel and surround strengthening respectively. Furthermore, test results showed that the diagonal-strengthened system is one of the most effective methods for strengthening an RC slab with openings in terms of load-carrying capacity, stiffness and crack patterns.
\end{abstract}

Keywords: RC slab; RC-strengthening; GFRP composite beam; crack pattern; failure mode

\section{Introduction}

In general, building codes are intended to protect people by preventing severe damages or collapse of that building in use. Furthermore, collapse or severe damages of critical buildings such as schools, 
hospitals and public buildings may cause more devastating effects, with possible life loss. Seismic codes in buildings did not apply in Korea until 1988 since the country was considered to be located in a zone with low seismicity. Due to that fact, buildings constructed prior to 1988 in Korea cannot be considered safe, and need upgrading or strengthening of their structural elements. In particular, strengthening efforts of structural elements in school buildings that do not comply with current building codes have been made by the government or the local government in Korea since 2010 after the earthquake of Sichuan (2008) in China. During the strengthening of school reinforced concrete buildings, there were many cases when the strengthening of openings in RC slabs to accommodate new bathrooms, elevators or utility ducts were necessary. It is well known that creating openings in slabs can significantly decrease the load-carrying capacity of RC structure due to the discontinuity of structural elements including the cutting of both concrete and reinforcing steel $[1,2]$. The strengthening methods using fiber-reinforced polymer (FRP) composites have been widely used because FRP strengthening methods seem to have easy handling, lighter equipment for installation and less concern about corrosion in strengthened surface as compared to conventional methods such as steel jacketing method [3-5]. However, the performance or data of FRP-strengthened RC slabs with opening is rather limited although the performance of FRP-strengthened RC has received significant attention. Several analytical or experimental researches have reported on FRP-strengthened RC slab with openings [6-10]. Seliem et al. [11] reported the results of CFRP strengthened RC slab after having large openings cut out at the center of a slab in the positive moment region. In their investigation, three different strengthening types, externally bonded CFRP laminates, externally bonded CFRP laminates with CFRP anchors and near surface mounted (NSM) CFRP strips, were used for the evaluation of flexural capacity of slab. From the tests, it was found that the slab strengthened with NSM CFRP strips had a higher load-carrying capacity in comparison to the slab strengthened with externally bonded CFRP laminates if using significantly less area of FRP, and the use of externally bonded CFRP laminates slightly increased the flexural strength of the slab with opening while significantly enhancing its stiffness. Test results also showed that creating an opening in the slab reduces its strength by as much as $18 \%$ up to failure. Casadei et al. [12] presented the experimental results of one-way slabs with openings from on existing parking garage externally strengthened with CFRP laminates. In this study, a total of six one-way square slab specimens were used from an existing parking garage building as a test bed. Test results showed that the use of CFRP laminates in slab strengthening was effective with an increase in load by approximately 30\%, and shear failure was found to be the controlling mechanism when cutouts were placed in the negative moment region of one-way slabs. Smith et al. [13] reported the experimental and analytical results of fiber reinforced polymer (FRP) strengthened one-way spanning reinforced concrete (RC) slabs with central cutouts for four wide slabs with cutouts and two narrow slabs without cutouts. Test results indicated that all FRP-strengthened slabs achieved a higher load-carrying capacity than their unstrengthened control counterparts. In addition, all strengthened slabs failed by debonding initiating at intermediate cracks (IC debonding) and in the case of the slabs with cutouts, the critical cracks were diagonal and originated from the corners of the cutout. Also, an analytical model was able to capture the different slab bending actions in addition to the debonding failure of the strengthened slabs. Enochsson et al. [14] showed the results of laboratory tests on 11 slabs with openings including six slabs strengthened with carbon fiber reinforced polymers (CFRPs) sheets. Strengthened slabs were compared with traditionally steel reinforced slabs and 
without openings in slab. The results showed that slabs with openings can be strengthened with externally bonded CFRP sheets and the performance was even better than for traditionally steel reinforced slabs. Also, the numerical and analytical evaluations showed a good agreement with the experimental results.

This investigation provides additional data to the investigations conducted by the other researchers. Specimens, one-half scale, have been designed and fabricated to reflect the most common RC bathroom slab used in school buildings. Also, the investigation described in this paper supports the use of an FRP composite beam as a means of strengthening or repairing of RC slabs with openings, when RC slabs do not satisfy load-carrying capacity or current design codes requirements.

\section{Experimental Program}

The experimental program is focused on examining the structural performance of RC slabs strengthened with glass fiber reinforced plastic composite beam near openings. Four simply-supported RC slabs, one with no strengthening and three that were strengthened with the GFRP system, were carefully investigated as a measure of load-carrying capacity and stiffness.

\subsection{Material}

The following materials were used in this study: type I/II Portland cement which meets the Korean standards KS L5201 [15], 19 mm maximum size of crushed coarse aggregate with a specific gravity of 2.64 , natural sand with a specific gravity of 2.56 and a fineness modulus of 2.42 . The mix design of concrete was prepared with the following: ordinary Portland type I/II cement $410 \mathrm{~kg} / \mathrm{m}^{3}$, aggregate $1629 \mathrm{~kg} / \mathrm{m}^{3}$, water-cement ratio of 0.48 . The used mix proportions were intended to have a normal weight and a target average compressive strength of $21 \mathrm{MPa}$ at 28 days, respectively. For strengthening, commercially available glass fiber containing (GFRP) composite beam as shown in Figure 1 was used. Table 1 shows the mechanical properties of the GFRP composite beams provided by the manufacturer. Glass fiber containing composite beam has dimensions of $130 \mathrm{~mm}(\mathrm{~W}) \times 12 \mathrm{~mm}(\mathrm{H})$.

Figure 1. Glass fiber reinforced plastic (GFRP) composite beam.

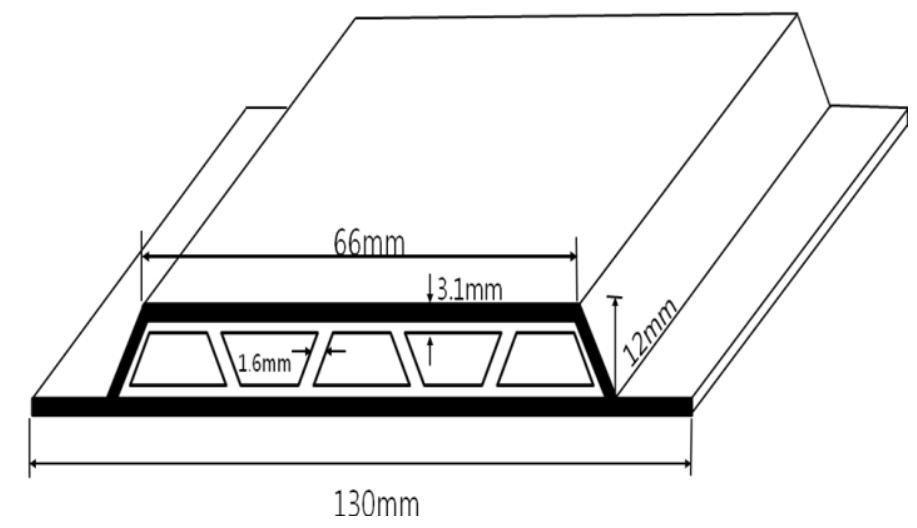


Table 1. Mechanical properties of the Glass fiber reinforced plastic (GFRP) composite beams.

\begin{tabular}{ccc}
\hline Type & Unit & Property \\
\hline Cross Section & $\mathrm{mm}^{2}$ & 1312 \\
Tensile Strength & $\mathrm{MPa}$ & 418 \\
Compressive Elastic Modulus & $\mathrm{GPa}$ & 28 \\
Ultimate Elongation & $\%$ & 2.1 \\
\hline
\end{tabular}

\subsection{Slab Specimens}

A total of four RC slabs having dimensions of $2000 \mathrm{~mm}(\mathrm{~W}) \times 150 \mathrm{~mm}(\mathrm{~T}) \times 3000 \mathrm{~mm}(\mathrm{~L})$ were fabricated using the 28-day average concrete compressive strength of $23.4 \mathrm{MPa}$ and the average concrete elastic modulus of $25.63 \mathrm{GPa}$. The average 28-day concrete compressive strength was obtained from the four standard cylinder specimens $(150 \mathrm{~mm} \times 300 \mathrm{~mm})$. The slab dimensions were chosen based on one-half scale of the typical bathroom slabs of school buildings. Each slab has two symmetric openings of the same size, with dimensions of $300 \mathrm{~mm}(\mathrm{~W}) \times 400 \mathrm{~mm}(\mathrm{~L})$, as shown in Figure 2. The openings were created with a concrete saw-cutting machine, and then four cut-edges were smoothed out by $100 \mathrm{~mm}$ thickness of cement mortar. Actually, these openings were intended for use in bathroom installations or utility purposes in the existing building slabs. Each slab had 12 and 8 HD (high tension deformers) $10 \mathrm{~mm}$ bars as bottom and top reinforcement in longitudinal and transverse directions, respectively. Details of slab reinforcement are given in Figure 2. All steel bars used in the slabs have yield strength of $400 \mathrm{MPa}$. Before bonding the GFRP composite beams around the openings, the slab surface was first sandblasted, cleaned and dried, and the epoxy was uniformally applied. The properties of the used epoxy resin have tensile strength of $44.9 \mathrm{MPa}$, flexural strength of 97.0 MPa and density of $1.21 \mathrm{~g} / \mathrm{cc}$. To improve the bond between the GFRP and concrete in this study, commercially available power pins were used in the lips of GFRP composite beams. The application of GFRP composite beams was undertaken in accordance with the requirements of the manufacturer of the GFRP composite system. All the strengthened slabs were tested approximately 90 days after casting, and two weeks after applying the GFRP composite beams.

Figure 2. Details of reinforcement.

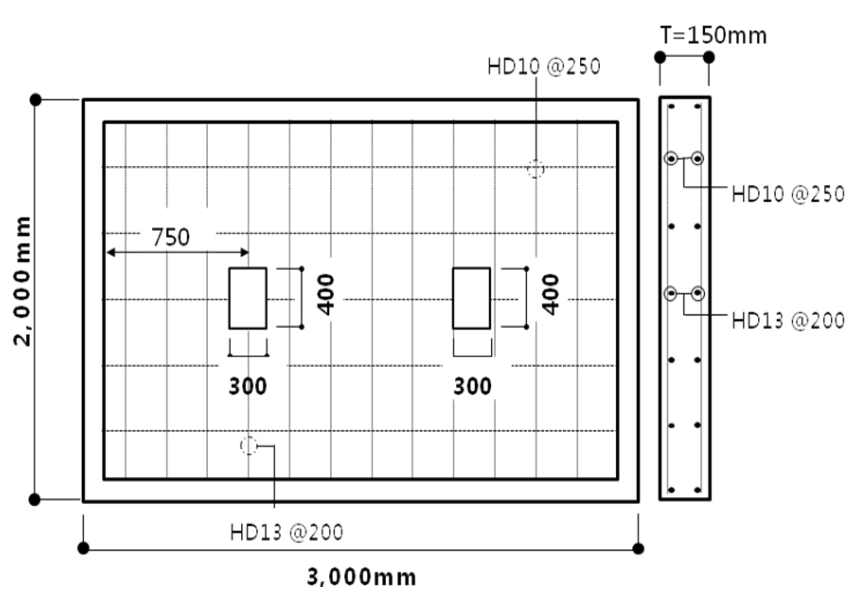

In this study, four different strengthening configurations of GFRP composite beam were used for comparison of their effectiveness. Details of strengthened slabs are shown in Figure 3 with the 
positioning of the FRP composite beams around the openings. The strengthening configurations used in this study were chosen based both on economic considerations and technical aspects of engineering. Also, these types of strengthening were selected to examine the potential use of GFRP composite beams to enhance the load-carrying capacity of RC slabs with openings. The first slab $\left(\mathrm{S}_{\mathrm{U}}\right)$ without FRP strengthening served as the control slab. The other three slabs $\left(S_{D}, S_{P}\right.$ and $\left.S_{S}\right)$ were strengthened with FRP composite beams in diagonal, parallel and surround at the near openings respectively.

Figure 3. Strengthened configurations of (a) diagonal; (b) parallel; (c) surrounding slabs with openings.

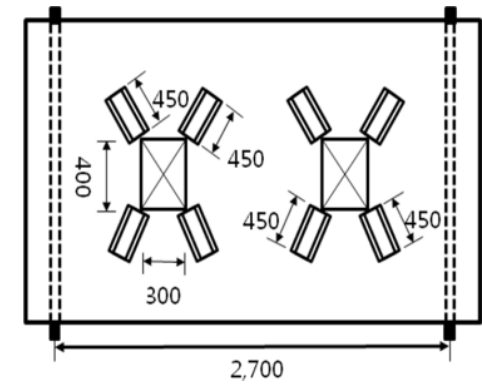

(a)

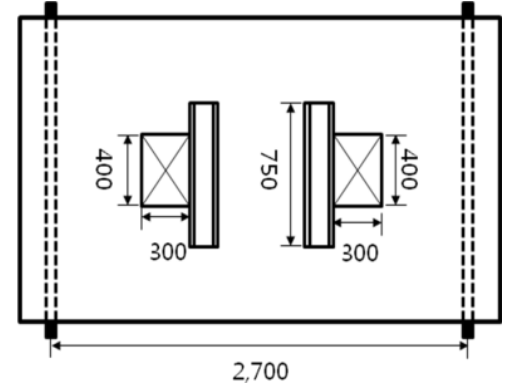

(b)

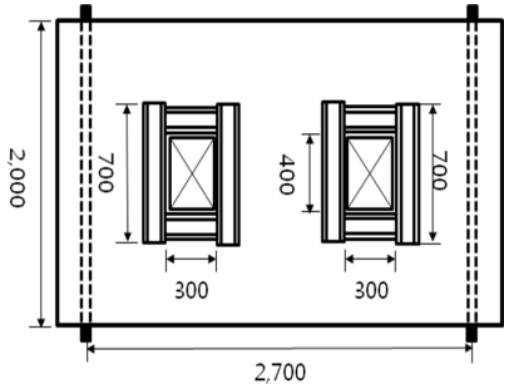

(c)

\subsection{Test Setup and Procedure}

In this experiment, each slab specimen was tested under simply-supported conditions with a clear span of $2.7 \mathrm{~m}$. All slab specimens were subjected to monotonic compressive loading using a $500 \mathrm{kN}$ of Material Testing System (MTS) actuator (MTS, Eden Prairie, MN, USA) with maximum stroke of 150 $\mathrm{mm}$. The load was applied at the center of the specimen at a rate of $2.0 \mathrm{~mm} / \mathrm{min}$. Also the midspan displacement of each specimen was measured using linear variable differential transformer (LVDT). Furthermore, in order to trace the crack development and propagation, two people were placed directly under the slab during tests to mark up the crack propagations as they appeared at the bottom of the slabs with a frequency of every $1 \mathrm{kN}$ of the load changed, as shown in Figure $4 \mathrm{a}$. The configurations of the slab tests are shown in Figure 4. First, unstrengthened slab was tested to failure to investigate the load-carrying capacity, crack pattern and stiffness as a control specimen.

Figure 4. Test setups of (a) unstrengthening; (b) surround strengthening; (c) diagonal strengthening; (d) parallel strengthening for the various strengthening configuration.

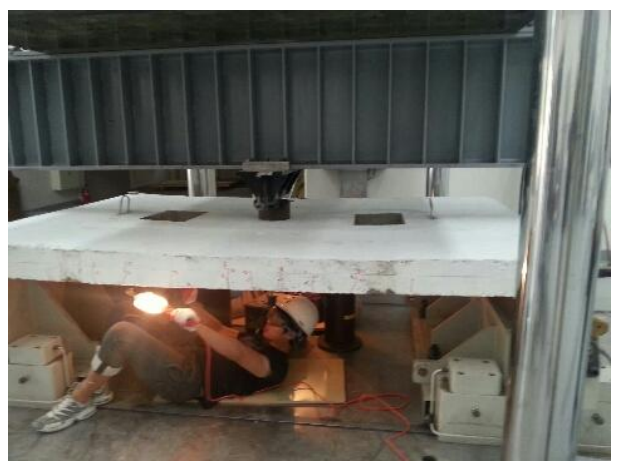

(a)

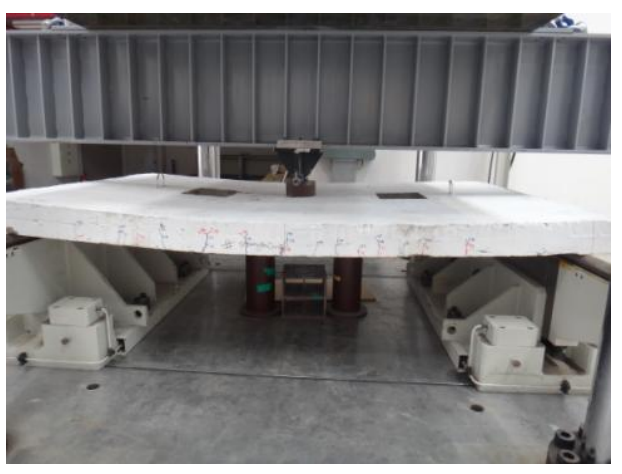

(b) 
Figure 4. Cont.

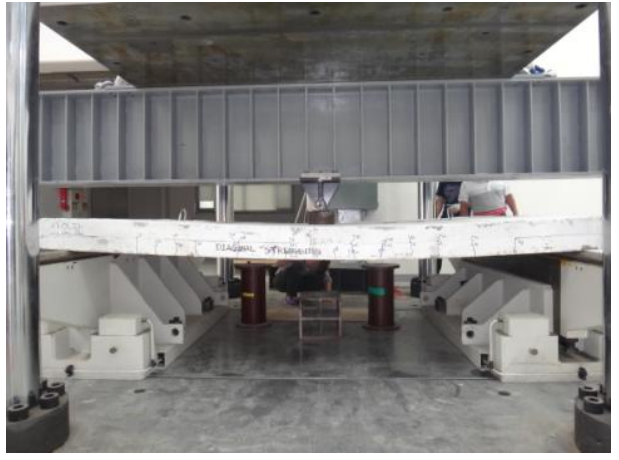

(c)

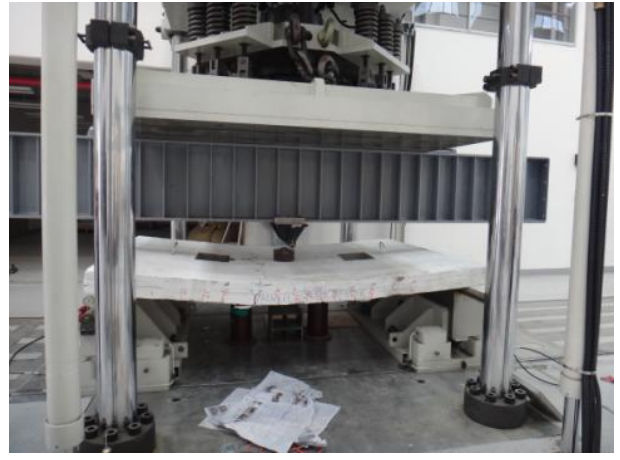

(d)

\section{Test Results and Discussions}

\subsection{Load-Deflection}

The measured maximum load and the corresponding deflections are given in Table 2. The maximum load of the control specimen was $71.91 \mathrm{kN}$. The maximum loads of all tested slabs were $92.59 \mathrm{kN}, 86.80 \mathrm{kN}$ and $80.39 \mathrm{kN}$ for diagonal, parallel and surround strengthening respectively. Therefore, the strengthened slabs for diagonal, parallel and surround strengthening seem to raise the load-carrying capacity by $29 \%, 21 \%$ and $12 \%$ over that of the control specimen, respectively. The use of the GFRP composite beam has relatively increased the load-carrying capacity of slab because of the rigidity of the GFRP composite beams. However, the strengthening slabs with FRP system reduced its deflection at the maximum load by $28 \%, 13 \%$ and $21 \%$ over that of the control specimen for diagonal, parallel and surround strengthening respectively. The load-carrying capacity of strengthened slabs from this investigation was similar to that found in the one-way slabs with openings strengthened with CFRP laminates by Casadei et al. [12].

Table 2. Test results of loads and deflection.

\begin{tabular}{|c|c|c|c|}
\hline \multicolumn{4}{|c|}{ SpecimenMaximum Load $(\mathrm{kN})$ Deflection at the Maximum Load $(\mathrm{mm})$ First Cracking Load $(\mathrm{kN})$} \\
\hline $\mathrm{S}_{\mathrm{U}}$ & 71.91 & 69.05 & 22 \\
\hline $\mathrm{S}_{\mathrm{D}}$ & 92.59 & 52.16 & 25 \\
\hline $\mathrm{S}_{\mathrm{P}}$ & 86.8 & 62.4 & 19 \\
\hline $\mathrm{S}_{\mathrm{S}}$ & 80.39 & 57.18 & 22 \\
\hline
\end{tabular}

The observed load-deflection curves up to failure are shown in Figure 5. The linear relationship between load and deflection can be observed up to the first cracks which opened at the bottom of slabs. The relationship continues nearly linearly until deflection increases without a substantial increase of load. At this point, de-bonding was initiated at the one of corners of opening between GFRP composite beam and concrete interface. Under this condition, it was found that the tension steel reinforcement already yielded and major cracks became wider. Test results indicated that the strengthened slabs may have an increased stiffness of $15.30 \%, 18.6 \%$ and $9.87 \%$ over that of the control specimen for diagonal, parallel and surround strengthening respectively. Also, all the strengthened slabs exhibited higher ductility than the control specimen, sometimes as much as $23 \%$. This type of behavior is caused 
by the gradual steel yielding in the slab and it reached failure or strengthening FRP still had the ability to mitigate sudden failure of slabs. However, the test results by Smith [13] reported a loss of ductility when FRP system was added in RC slabs. This contrary result may come from the different span length and loading type for the test. Thus, it is necessary to verify such a controversial result through future research. Also, the initial stiffness of strengthened slabs, which is represented by a slope on the graph up to the moment when the first crack occurred, was higher for all FRP strengthened slabs than the control slab. This means that the use of the GFRP composite beam increased the stiffness of slabs with openings due to the rigidity of the GFRP composite beam itself. From the test results, it can be concluded that diagonally-strengthened slab is one of the most effective strengthening methods for RC slab with openings in terms of load-carrying capacity, stiffness and crack patterns.

Figure 5. Load-deflection curves.

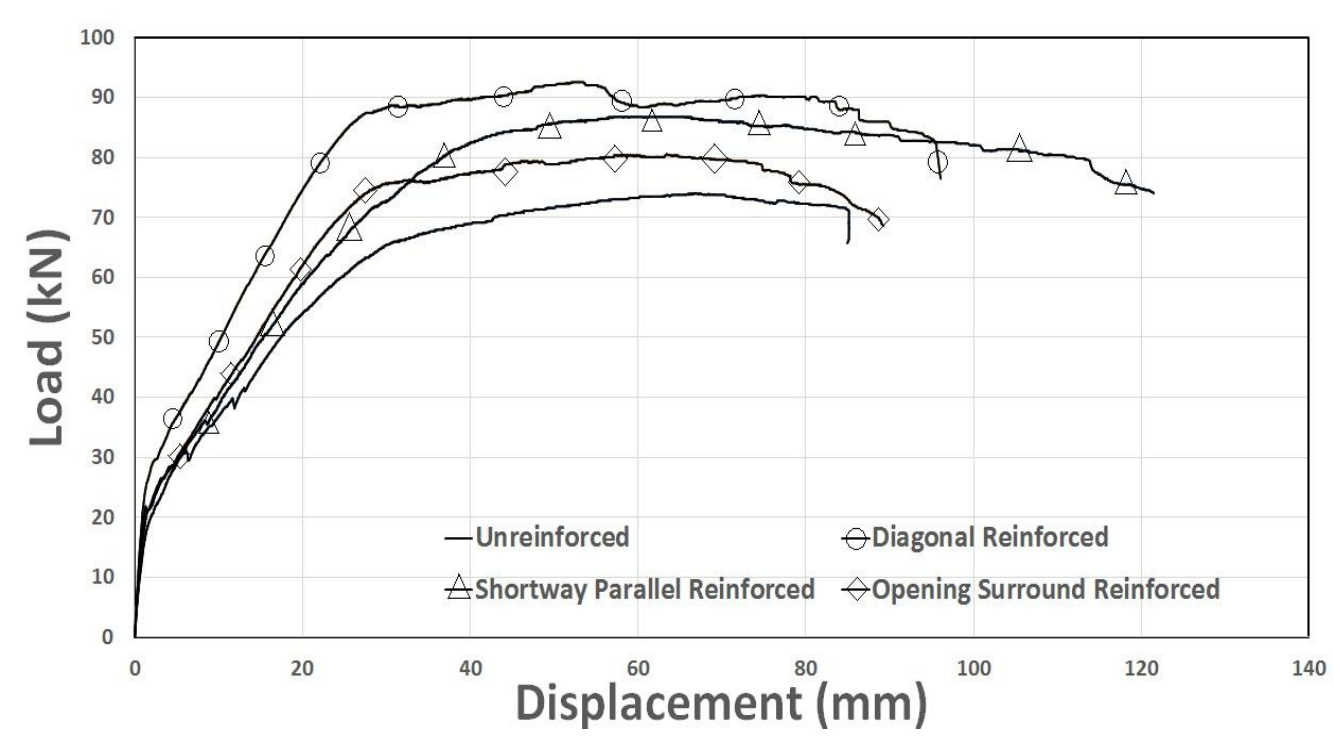

\subsection{Crack Patterns and Modes of Failure}

Figure 6 shows the final failure condition of the tested slabs. It was observed that the slab strengthened with GFRP composite beams failed by flexure due to the intermediate cracks between the two openings. As shown in Figure 6, all tested slabs had ultimately failed by debonding of GFRP composite beam with a wide-open crack, which originated from the corners of the opening and propagated towards the short length of the slab. During the tests, an almost identical failure sequence was observed in all strengthened slabs as compared to the control slab. Also, crack propagation was increased gradually until the load approached almost its maximum, and after that point, crack width became wider. 
Figure 6. Failure Modes of (a) unstrengthened; (b) surround strengthening; (c) parallel strengthening; (d) diagonal strengthening.

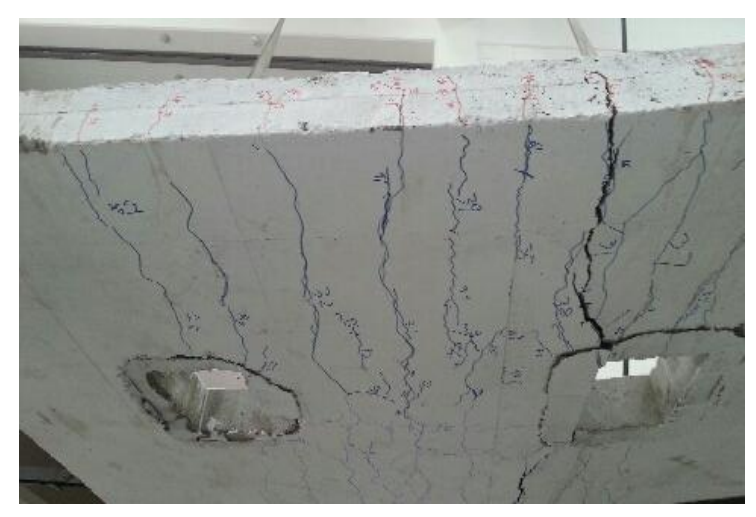

(a)

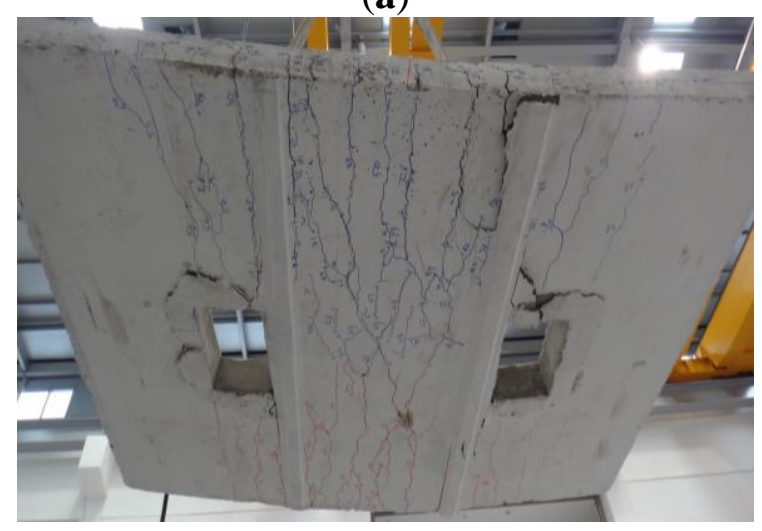

(c)

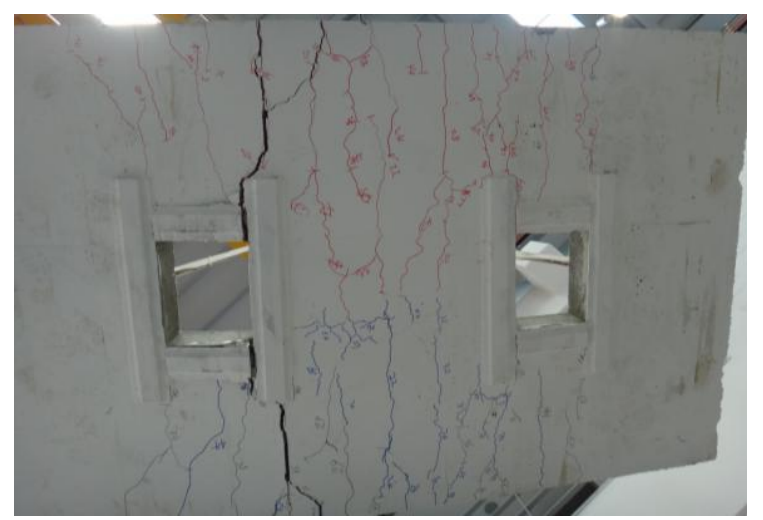

(b)

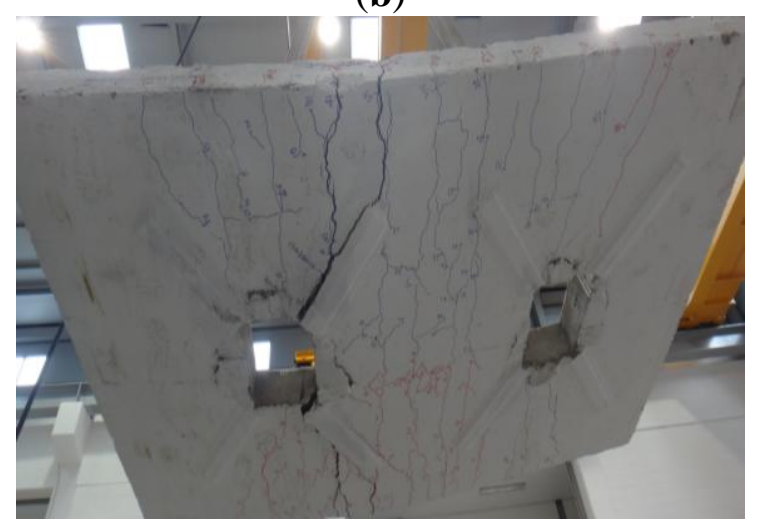

(d)

The detailed schematic final crack patterns are given in Figure 7. For the control specimen, first cracks were detected in the midspan region at the load of $22 \mathrm{kN}$ into the transverse direction. At the load of $65 \mathrm{kN}$, the main transverse cracks reached approximately $0.5-1.0 \mathrm{~mm}$ in width for the control slab. The first cracks of the strengthened slabs also detected in the midspan region at the loads of 25 , 19 and $22 \mathrm{kN}$ for diagonal, parallel and surround strengthening, respectively. The main transverse cracks of the strengthened slabs reached the width of approximately $0.3-0.4 \mathrm{~mm}$ at an average load of approximately $65 \mathrm{kN}$. Unexpectedly, the slight differences between the control and GFRP composite beam strengthened slabs for the first cracking load were probably due to the relatively long span or the loading configuration used in this investigation. Diagonal cracks were also detected from the near openings of the strengthened slab as the load increased. Compared to the control slab, the strengthened slabs showed more and longer diagonal cracks. Also, there were no significant differences in crack pattern and the extent of cracks between different strengthening types in this study. A similar result was found in the result of one-way spanning RC slabs with cutouts using FRP composites by Smith et al. [13]. Furthermore, strengthening the slab with FRP system resulted in a multi-direction crack mechanism than that of the control specimen. This result may indicate that crack propagation in $\mathrm{RC}$ slabs could be controlled with FRP strengthening technique for a particular case when required. 
Figure 7. Crack patterns of (a) unstrengthened; (b) parallel strengthening; (c) diagonal strengthening; (d) surround strengthening.

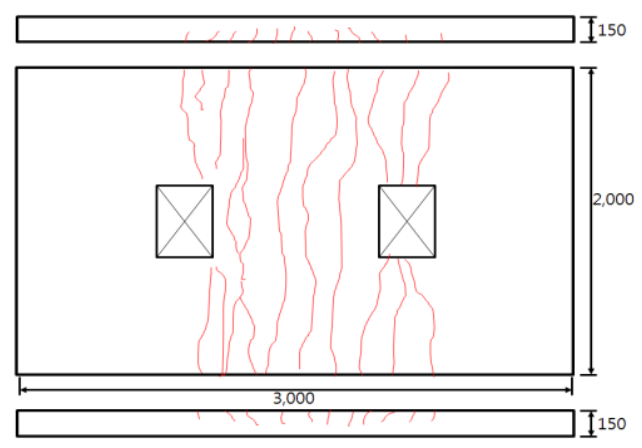

(a)

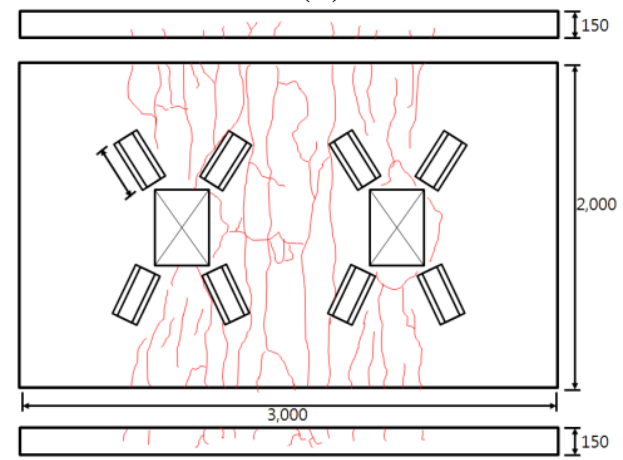

(c)

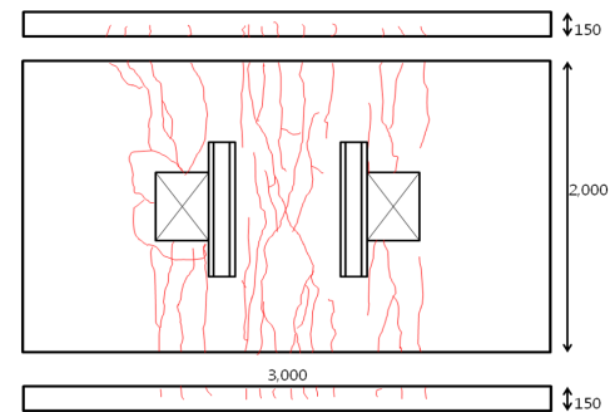

(b)

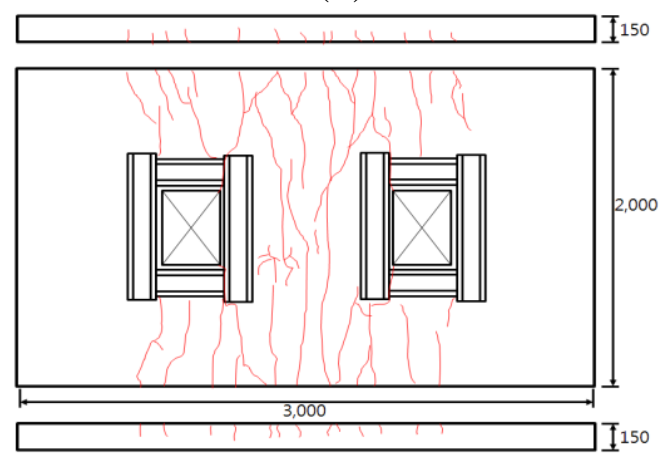

(d)

\section{Conclusions}

This paper described the results of RC slabs with two openings strengthened with GFRP composite beam. One control slab without FRP strengthening and three slabs with FRP strengthening were investigated for their effectiveness. Based on the test results, it can be concluded that the investigated strengthening types can be used for strengthening or upgrades of structural capacity of existing RC slabs with openings, since all strengthened slabs seem to raise the load-carrying capacity approximately by an average of $20 \%$. Also, diagonally-strengthened slab showed to be one of the most effective ways for load-carrying capacity, stiffness and crack patterns. It was also observed that the slab strengthened with GFRP composite beams failed by flexure due to the intermediate cracks and debonding of GFRP composite beam with a wide-open crack. Also, there were no significant differences in crack patterns and the extent of cracks between different strengthening types in this study.

\section{Acknowledgments}

The study has been supported by Basic Science Research Program through the National Research Foundation of Korea (NRF) funded by the Ministry of Education, Science and Technology (No. 2012005170) and Kyungpook National University Research Fund (2013).

\section{Conflicts of Interest}

The authors declare no conflict of interest. 


\section{References}

1. Florutt, S.C.; Stoian, V.; Tamas, N.G.; Diaconu, D.D. Retrofitting of Two-Way RC Slabs with and without Cut-Out Openings by Using FRP Composite Materials. EMESEG'10 Proceedings of the 3rd WSEAS International Conference on Engineering Mechanics, Structures, Engineering Geology, Corfu Island, Greece, 22-24 July 2010; pp. 245-250.

2. American Concrete Institute. Guide for the Design and Construction of Externally Bonded FRP Systems for Strengthening Concrete Structures; ACI 440.2R-08; American Concrete Institute: Detroit, MI, USA, 2008.

3. Mosallam, A.S.; Mosalam, K.M. Strengthening of two-way concrete slabs with FRP composite laminates. Constr. Build. Mater. 2003, 17, 43-54.

4. Maaddawy, T.E.L.; Soudki, K. Strengthening of reinforced concrete slabs with mechanically-anchored unbonded FRP system. Constr. Build. Mater. 2008, 22, 444-455.

5. Ellouze, A.; Ouezdou, M.B.; Karray, M.A. Experimental study of steel fiber concrete slabs part I: Behavior under uniformly distributed loads. Int. J. Concr. Struct. Mater. 2010, 4, 113-118.

6. Tan, K.; Zhao, H. Strengthening of openings in one-way reinforced-concrete slabs using carbon fiber-reinforced polymer systems. J. Compos. Constr. 2004, 8, 393-402.

7. Smith, S.T.; Hu, S.; Kim, S.J.; Seracino, R. FRP-strengthened RC slabs anchored with FRP anchors. Eng. Struct. 2011, 33, 1075-1087.

8. Elsayed, W.; Ebead, U.; Neale, K. Mechanically fastened FRP-strengthened two-way concrete slabs with and without cutouts. J. Compos. Constr. 2009, 13, 198-207.

9. Kim, J.J.; Noh, H.-C.; Reda, T.; Mahmoud, M. Flexural failure design criteria for retrofitted RC slabs using FRP-UHPC hybrid system. J. Korean Soc. Adv. Compos. Struct. 2013, 3, 11-18.

10. Ebead, U.; Marzouk, H.; Lye, L.M. Strengthening of Two-Way Slabs Using FRP Materials: A Simplified Analysis Based on Response Surface Methodology. 2nd World Engineering Congress, Sarawak, Malaysia, 22-25 July 2002; pp.1-6.

11. Siliem, H.M.; Sumner, E.A.; Seracino, R. Field Testing of RC Slabs with Openings Strengthened with CFRP. In Proceedings of the Fourth International Conference on FRP Composites in Civil Engineering (CICE2008), Zurich, Switzerland, 22-24 July 2008.

12. Casadei, P.; Nanni, A.; Ibell, T. Experiments on Two-Way RC Slabs with Openings Strengthened with CFRP Laminates. In Proceedings of Advancing with Composites, Milano, Italy, 7-9 May 2003.

13. Smith, S.T.; Kim, S.J. Strengthening of one-way spanning RC slabs with cutouts using FRP composites. Constr. Build. Mater. 2009, 23, 1578-1590.

14. Enochsson, O.; Lundqvist, J.; Taljsten, B.; Rusinowski, P.; Olofsson, T. CFRP strengthened openings in two-way concrete slabs-An experimental and numerical study. Constr. Build. Mater. 2007, 21, 810-826.

15. Korean Standards Service Network. Standard Specification for Portland Cement; KS L 5201; Korean Standards Service Network: Seoul, Korea, 2006.

(C) 2013 by the authors; licensee MDPI, Basel, Switzerland. This article is an open access article distributed under the terms and conditions of the Creative Commons Attribution license (http://creativecommons.org/licenses/by/3.0/). 